\title{
Aspects of Academic Performance and Ethics in the Transition to eLearning Caused by the Actual Pandemic - A case study
}

\author{
Petre Lucian Ogrutan ${ }^{1}$, Lia Elena Aciu ${ }^{2}$ \\ ${ }^{1}$ Transilvania Univeristy of Brasov, Electronic and Computer department, Politehnicii no.1, Brasov, Romania \\ ${ }^{2}$ Transilvania Univerisity of Brasov, Electrical engineering department, Politehnicii no.1, Brasov, Romania
}

\begin{abstract}
In the actual context of a great diversity of information sources, the discipline of Ethics and Academic Integrity (EAI) was introduced recently in the first year of the Master's studies. As part of the school activity, the access to anti-plagiarism software was made available to teachers and students. The current pandemic has forced the transition from classical classes to the use of the eLearning platform. In this paper the application of the methods of antiplagiarism verification to the distance teaching and the obtained results are described. The conclusions are expressed by comparing the results obtained for the discipline developed through the eLearning platform with those obtained in the previous years in a face-toface teaching manner and with those of the EAI discipline carried out in the first semester of this academic year as well.
\end{abstract}

Keywords - Engineering education, Digital academic dishonesty, Plagiarism, academic integrity in higher education, eLearning

\section{Introduction}

In the 2018-2019 academic years, the discipline of Ethics and Academic Integrity (EAI) was introduced for the first time to all the master programs at Transilvania University of Brasov as response to a recent increase in plagiarism cases, revealed in the media.

DOI: 10.18421/TEM92-31

https://doi.org/10.18421/TEM92-31

Corresponding author: Lia Elena Aciu,

Transilvania University of Brasov, Romania.

Email: lia aciu@unitbv.ro

Received: 14 April 2020.

Revised: 28 April 2020.

Accepted: 07 May 2020.

Published: 27 May 2020.

(cc) BY-NC-ND (C) 2020 Petre Lucian Ogrutan \& Lia Elena Aciu; published by UIKTEN. This work is licensed under the Creative Commons Attribution-NonCommercialNoDerivs 4.0 License.

The article is published with Open Access at www.temjournal.com
Within the Master's program of Electronics and Communications Systems from the Faculty of Electrical Engineering and Computer Science, the discipline of EAI has been focused on producing documentation dedicated to publishing or patenting in compliance with the rules of professional ethics. Therefore, students are evaluated through a theoretical test, but also by applying a scientific paper that they had to elaborate, which is based on their diploma project from the bachelor's studies, on their own passed or current research. All the papers elaborated by the students are checked against the anti-plagiarism with the Turnitin application. The results obtained at the EAI course were good, proving that besides the theoretical aspects of ethics, students had the opportunity to learn both, how to quote from bibliography and how to draw up a scientific paper.

Due to the pandemic that broke out in Romania in March 2020, the regular courses were suspended and moved to the distance education system, using video conferencing and uploaded materials on the university's eLearning platform. For undergraduate students that are in their final year, the last semester of studies is important. These students have to elaborate their diploma project, so they have to make sustained efforts to meet the deadlines. For example, at the course of Interfacing and Peripheral Equipments (IPE) the discipline master considered that the support of the courses by videoconference and the study of the information materials downloaded from the eLearning page are not sufficient. It was considered as the main cause by which students will only learn in the session, and therefore there is a risk of not promoting. At the final year the failed exams may prevent the proper elaboration of the diploma project, so it has to be avoided. For this reason, it was proposed to students to solve some homework based on the available materials, even with the consultation of Internet resources. In order to convince the students to do this additional homework, a bonus proportional to the grade obtained for each topic was proposed. All the results have been verified with Turnitin to avoid 
taking over solutions from the Internet by the students or copy them from their colleagues. In this paper the results obtained are presented in the way of conducting the discipline Interfacing and Peripheral Equipments (IPE), identified improvements and the difficulties encountered.

\section{The Academic Ethics}

A new feature of the professional activity is the increased independence of the engineers (e.g. entrepreneurs or employees in modern companies). The ethical standards specific to a certain profession oblige the observance of additional rules to those required by law.

Ethics can be classified as follows [1]:

1. The common ethic shared by most people, which protect people from negative interference with the others

2. Personal ethics is applied where common ethics is unclear

3. Professional ethics, which in general has been synthesized in the form of ethical codes by national and international associations. In engineering, the main issues contained in these codes refer to intellectual property (and copyright), but new environmental protection guidelines appear, along with particular aspects. IEEE has proposed a code of ethics and Transilvania University of Brasov has a code of ethics included in the University's Charter.

Professional ethics is divided into preventive ethics, with the role of preventing professional errors and inspirational ethics, which tends to improve people's lives and protect the environment. In 2000, the body accrediting engineering studies in the USA (Accreditation Board for Engineering and Technology (ABET)) added new accreditation criteria in relation to engineering creations and society [2]. Thus, criterion 6 requires the educational institution to ensure "an understanding of professional and ethical responsibility." Moreover, criterion 8 requires students to receive "the broad education necessary to understand the impact of engineering solutions in a global and social context." Criterion 10 requires students to receive "knowledge of contemporary issues."

E3 Team (Exploring Ethical decision-making in Engineering) studies the lack of ethics in engineering graduates [3]. A study quoted by the E3 Team shows that $60 \%$ of the 34,000 students surveyed admitted that they copied in the faculty once and 35\% several times (copy on homework, projects or exams). The E3 Team study shows that at the students who have copied bring about the probability of lack of honesty, which in return reflects that copying in the workplace increases. People who did not copy in the faculty reported $50 \%$ that they would not break the rules at the workplace, and those who copied multiple times only reported $10 \%$ that they would not break the rules. The reasons that determine an unethical behavior are: pressure of tasks, lack of time, importance of success, dislike of criticism. The hesitations for unethical behavior are due to the moral sense, conscience and risk of punishment.

Due to the widespread access to information technology-based Academic Dishonesty (AD) is constantly increasing [4], [5]. The components of AD are: cheating, plagiarism, fabrication, and facilitation. Ethical Dissonance is defined as the difference between the pervasiveness and the legitimacy of $\mathrm{AD}$ types. A recent research paper [4] states that in the virtual (digital) environment plagiarism is considered by students more legitimate than in classical learning environments (face to face learning). In another study conducted on a large number of students it is stated that in the digital environment, plagiarism is less penalized than in the classical activity [6]. The reason invoked by students to justify dishonesty is to maintain a good opinion about them. Moreover, some educational institutions do not publish the dishonesty cases in order to maintain their acquired prestige.

Methods for reducing $\mathrm{AD}$ are studied in the academic and research communities. A complex software system for authenticating and verifying students' identity in distance learning is TeSLA (an Adaptive Trust-based e-assessment System for Learning). The paper [7] describes the challenges in the field of plagiarism in education (face-to-face and eLearning) and the measures that can be taken to reduce the phenomenon. The paper is focused on dishonesty in remote evaluations. Students consider that online assessment has advantages and disadvantages. Students' doubts about online evaluation mode are analyzed in [8]. The paper [9] addresses the correlation between plagiarism and academic outcomes. Even if plagiarized works are rated above average, students who plagiarize have lower grades than average at final assessments. A study published in the paper [10] attempts to elucidate how new technologies and especially the Internet affect dishonesty. The study shows that new technologies do not generate dishonesty but only replace the old methods. The frequency of plagiarism cases was no higher when sending materials online than when sending classic ones. The work was elaborated within the TeSLA program. Paper [11] analyzes the causes of plagiarism through a statistical study with student participants. The conclusions regarding the paper are: the first cause of plagiarism is the existence of the possibility of it - the information is available on the Internet. Plagiarism is 
not caused by the Internet, but existing online information can be a catalyst. The second cause is some difficulty for students to take responsibility for their actions.

There are also studies that analyze the dishonesty situation in Romania. The paper [12] analyzes cheating in several universities due to the influence of colleagues and the educational process. A large study of AD in Romania [13] shows that out of the 1127 students participating in the study, 613 carried out activities classified in $\mathrm{AD}$ and suffered the consequences, 435 carried out $\mathrm{AD}$ activities and did not suffer consequences and 53 did not carry AD activities. The percentage of $95 \%$ of students who have carried out $\mathrm{AD}$ activities is high and worrying. A summary of the published information on AD behavior and the connection with dishonesty at work place in Romania and in the world is analyzed in [14]. Many cited studies show that AD behavior during college is a factor that predisposes to continuing this behavior at the workplace, too. A comparative study of AD behavior in several European countries (Austria, Portugal, Romania, Spain) shows that in Romania the percentage of students with AD behavior is relatively small comparing to that of Austrian students, for example [15]. One of efficient methods mentioned by the authors to reduce $\mathrm{AD}$ behavior is to increase the punishment.

\section{Academic Results Obtained in Face-to-face Learning Compared to eLearning}

\subsection{Academic Results at the Ethics and Academic Integrity Course}

The EAI course was held for the first time in the 2018-2019 academic years. In 2019-2020 academic years the course was modified according to the students' observations, and it became useful to and appreciated by the students. The course focused on practical aspects of patent applications and documentation, as well as on developing creativity in compliance with professional ethics standards. An important role was played by discussions of ethical cases, organized as Brainstorming meetings. The scientific paper elaborated by each student was presented in front of colleagues and discussed collectively. Some of the master's students are working on research projects with their teachers, these being the ones with the best achievements, and they are participating most actively in the discussions. The students' homework has been uploaded to the eLearning platform and has been verified for similarities with Turnitin software. A graph of the grades obtained by the students and the percentage of similarities is given in Figure 1, with the graph of the grades in red and the percentage of similarities in blue. A number of 38 homework papers were evaluated, and as a result, 37 students passed. One of the students had a $100 \%$ degree of similarity, and did not pass the exam. Later this student dropped out of university.

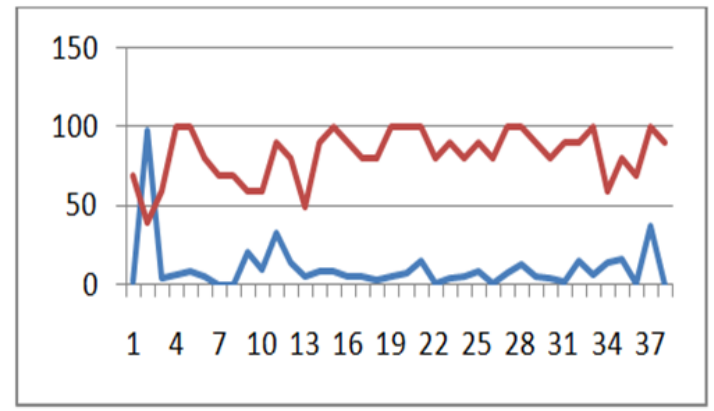

Figure 1. Student's academic results on the discipline of EAI (red, on a scale from 0-100) and the degree of similarity (blue, in percent)

The average grade obtained by the students was 8.26 (on a scale from 1 to 10), and the average degree of similarities was $10.81 \%$. In order to verify the correlation of the grade with the similarity fence, the Pearson correlation coefficient was applied, which was -0.308 , which means a weak negative correlation, natural for this situation?

\subsection{The Usefulness of Homework in the Transition to eLearning}

Since mid-March 2020, due to the corona virus pandemic in Romania, face-to-face learning had been dropped out, which caused changes and rethinking the educational process. The university's eLearning platform was functional at that time but was little used, only for students' access to study materials, as complementary to face-to-face education. During this transition, the eLearning platform made available to be used by two possibilities: videoconferencing and solving of themes through individual study based on uploaded materials and information from the Internet. In the IPE discipline that is supported in the Applied Electronics study program in the 2nd semester of $4^{\text {th }}$ year, an opinion poll was conducted to identify the students' preferences. The survey consisted of 2 questions: 1. Do you think that a good option is to take courses through the video conferencing system? 2. Is it a good option to be given topics to be solved through individual study? The answers were given on a Lickert scale from 1 to 5 , where 1 means strong disagreement and 5 total agreement. The distribution of student responses is given in Figure 2. 


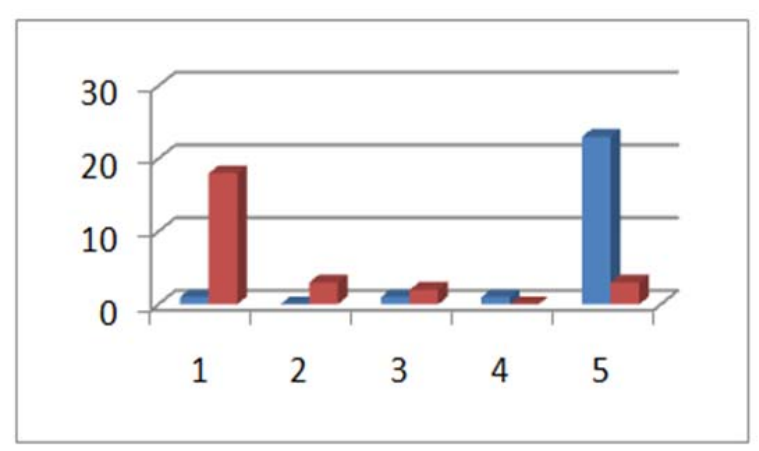

Figure 2. Distribution of students' answers to the questions how effective is the videoconference (blue) and solving the themes (red)

A number of 26 students answered the questionnaire and their preference was mostly for videoconferencing (an average of 4.7 compared to an average of 1.7 for solving homework). Their opinion is based on the fact that they appreciated the homework for about 4-5 hours for a topic. Hearing a course through videoconferencing requires much less effort. Students' reluctance to solve individual topics was analyzed in the study paper [16]. The students' opinion about the reasons for this reluctance was analyzed, and the most important reason identified as being invoked by the students was the lack of time. It is true that many students already have a job in the final year which makes their schooling more difficult. The questionnaire on the effectiveness of videoconferences and topics identified the opinion of the students but the task of solving the themes was kept, considering that the contribution of knowledge through these is absolutely necessary to pass the exam. The authors of the questionnaire were surprised by the low score they had to solve the issues, given the maturity of the students from $4^{\text {th }}$ year. Giroux analyzes in [17] the current culture he calls corporate and the negative effects on higher education. Giroux states that this culture develops individualism, and the search for the easiest ways to reach goals, with a negative impact on education. Most students at Applied Electronics are employed in multinational companies, so their attitude may be influenced by corporate culture. The search for the easiest way was confirmed by the questions asked by the students during the video conferences. Most of the questions refer to the minimum conditions for passing the exam and less to the content of the subject.

The students received 6 assignments, one per week. The homework was composed of 3 topics, one of 2 points with practical aspects and structures of peripheral equipment, one of 4 points with theoretical aspects of interfacing and a problem of 3 points in which it was required to connect a device at the host embedded system's bus or at input / output port. A point was awarded ex - officio. After solving a topic and uploading the solution on the eLearning platform, the new topic was displayed. Through a videoconferencing system the solutions were showed, the grades obtained and the questions or the doubts generated. After the display of the new topic discussions were organized. Exceeding a certain percentage of similarities was penalized as follows: 1 penalty point over $30 \%$, two penalty points for more than $50 \%$, unaccepted homework for more than $70 \%$. The first 3 homework contained only topics that could be solved based on the information uploaded by the teacher on the eLearning platform, and the last 3 homework contained a topic that had to be solved using Internet documentation. The group of students enrolled in this course was made up of 26 students, out of which 24 were active; the rest of 2 gave up studies before the pandemic started. A graph indicating the average of the grades obtained by the students (on a scale from 0 to 100) and by the percentages of similarities in percentages is given in figure 3 .

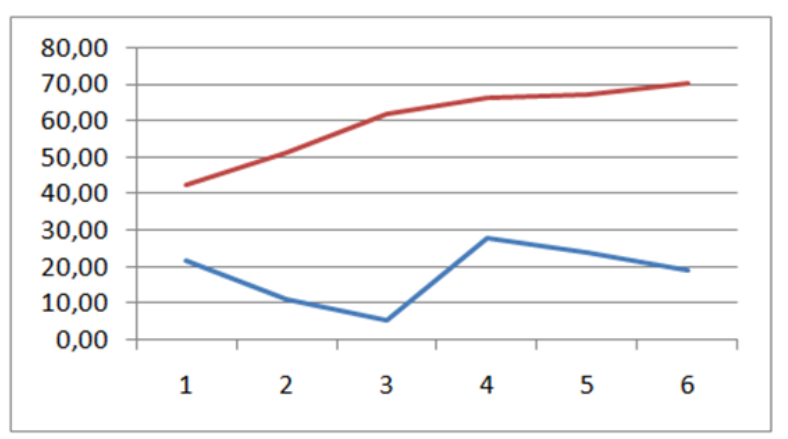

Figure 3. The average of the grades for solving 6 homeworks (red, on a scale from 0-100) and the degree of similarities (blue, in percentages), grouping by themes

It could be seen that the average of the grades increased as the students went through the information, understood the requirements of the assignments and they were within the deadline. Unfortunately, some of the students did not upload their homework, and their zero score did not enter the average calculation. A tendency to decrease the degree of similarities could be noticed in the first homework. Although there was no need for additional information on the Internet to solve the topics, it was still easier for some students to look online for solutions. On the third homework, the degree of similarity was low, most of the students looked only at the information materials uploaded on the platform. As it was natural, in the next 3 homeworks where information was needed on the Internet, the degree of similarity increased, however, with a decreasing tendency.

A graph showing the average of the marks obtained by the students in the 6 homeworks and of the percentage of similarities is given in Figure 4, with the graph of the grades in red and with the 
percentage of similarities in blue. The graph showing the average of the obtained grades and that of the percentage of similarities obtained in solving the themes can be compared with the one in Figure 1 from the face-to-face discipline. It can be noticed that the range of variation and the degree of similarity regarding the marks obtained in the case of the topics solved in the eLearning system is greater than in the face-to-face system.

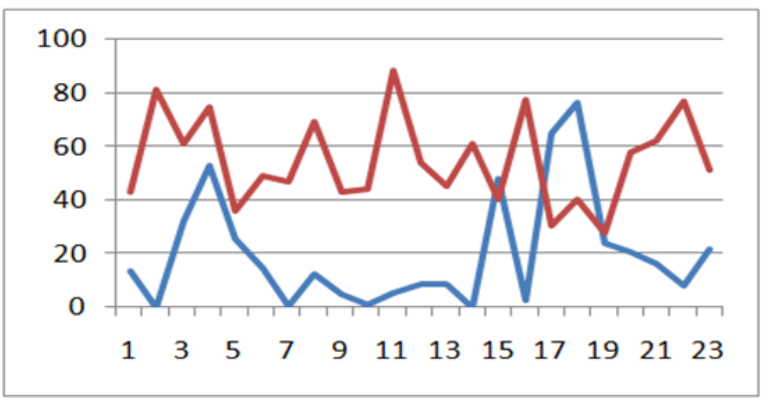

Figure 4. The average of the grades for solving 6 homeworks (red, on a scale from 0-100) and the degree of similarities (blue, in percentages), grouping by student

The graphs of the grades and the percentage of similarities for all students in each subject were not considered relevant. The authors considered the comparing graph for two students more relevant, the one with the best results and the one with the worst results. In Figure 5 the graph for the best student can be seen, with red the evolution of the grades and with blue the degree of similarity, and for the student with the weakest results with purple the graph of the grades and with the green the percentage of similarities.

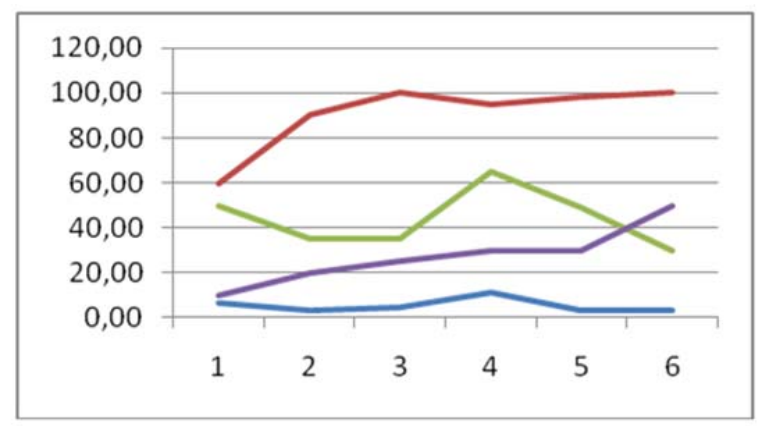

Figure 5. Evolution for the best student (grades on a scale from 0 to 100 with red, similarities with blue) and for the weakest student (with purple grades and with green the degree of similarities)

The extremes are noticed in Figure 4 and the connection between the academic performance and the percentage of similarities could be seen. The Pearson correlation coefficient for these data sets shows a strong negative correlation (-0.878). Synthesis data showing the average of the grades and of the degree of similarities in the case of face-toface and eLearning are given in Table 1. The average of the academic results on Interfacing and Peripheral
Equipments (IPE) in progress from face-to-face from the previous years is given in Table 2 .

Table 1. Synthesis data

\begin{tabular}{|c|c|c|c|}
\hline \multicolumn{2}{|c|}{ Face to face (EIA) } & \multicolumn{2}{c|}{ eLearning (IPE) } \\
\hline $\begin{array}{c}\text { Average } \\
\text { grades }\end{array}$ & $\begin{array}{c}\text { Average } \\
\text { similarities }\end{array}$ & $\begin{array}{c}\text { Average } \\
\text { grades }\end{array}$ & $\begin{array}{c}\text { Average of the } \\
\text { similarities }\end{array}$ \\
\hline 8.26 & $10.81 \%$ & 5.96 & $18.10 \%$ \\
\hline \multicolumn{2}{|c|}{ Correlation: -0.308} & \multicolumn{2}{|c|}{ Correlation: -0.37} \\
\hline
\end{tabular}

Table 2. Average academic results (grades)

\begin{tabular}{|l|l|l|l|l|l|}
\hline Year & $\mathbf{2 0 1 6}$ & $\mathbf{2 0 1 7}$ & $\mathbf{2 0 1 8}$ & $\mathbf{2 0 1 9}$ & $\mathbf{2 0 2 0}$ \\
\hline Grades & 5.68 & 4.77 & 5.05 & 4.15 & 5.96 \\
\hline
\end{tabular}

The average of the grades at IPE discipline in progress through eLearning is lower than the average of the marks in the works from the EAI discipline. A more realistic comparison is the one made with grades at the same discipline in previous years. It can be noticed that the average of the marks for the homework given through eLearning is higher than the average of the evaluations during the previous years.

\section{Conclusion}

The pandemic caused by COVID-19 virus forced the transition from face-to-face education to eLearning in mid-March 2020 at about halfway through second semester. At the EAI face-to-face course in the first semester for the first year students at the master's studies was introduced an evaluation of a sample consisting of writing a scientific paper, well documented and loaded on the eLearning platform for plagiarism verification. This sample was opened to all students for them to see in a transparent manner the importance of originality and the penalties for plagiarism. Based on the authors' experience with the EAI course, an original eLearning system was designed. This system was applied to students from Applied Electronics. In addition to taking the courses through videoconferencing, students had to solve several topics, preparing for these topics through individual study. The resolutions of the themes were verified with anti-plagiarism software, which in the students' view increased the difficulty of the homework.

The academic results obtained and summarized in Table 1 show that the grades obtained through distance learning are lower and the degree of similarities is higher. The sudden transition from face-to-face study in which discussions are initiated about each subject and the content of the course taught changes depending on the students' desire to the eLearning system in which the basis is the individual study was difficult. However, the evolution of the grades in Figure 4 shows that the adaptation to the new way of working was fast. 
Solving some topics during the semester was perceived by the students as a difficult activity. In the classical development the students attend the courses, but they learn and understand the subject only in the exam session. Solving homework forced them to learn more as they received different topics to be solved. It can be stated that the uniformly distributed work was more efficient, and the average of the grades for solving the themes is higher than the average of the grades from the previous years in the same discipline (Table 2). Of course, the average of the grades compared to the one from the EIA discipline is lower (Table 1), but the comparison is less relevant.

The comparison with the results from the EIA discipline was made in order to notice the differences of similarities. When solving the first homework the degree of similarity was high, the students were following the easiest path, and they were inspired by the bibliography (Fig. 3). On the second and third homework, the degree of similarity decreased. On topics 4,5 and 6 a topic which was introduced required information from the Internet and the degree of similarity increased again, this time in a justified way. It can be stated that there were no AD problems and the activity through eLearning; even though it is individual and there are accessible sources of information that did not make the students misuse Copy and Paste.

In order to collaborate in minimizing the effects of suspending the face-to-face courses, there was an understanding and solidarity of both, students and teachers. Thus, the transition to online courses and assessments was possible, academic performance reflected in the students' grades was maintained with respecting the requirements of academic ethics. Taking into account the difficulties encountered in distributing the student learning work throughout the semester, it is necessary to complete the courses with solving topic homework on the eLearning platform as bonuses for evaluation in the future.

\section{References}

[1]. Harris Jr, C. E., Pritchard, M. S., Rabins, M. J., James, R., \& Englehardt, E. (2013). Engineering ethics: Concepts and cases. Cengage Learning.

[2]. Cruz, J. A., \& Frey, W. J. (2003). An effective strategy for integrating ethics across the curriculum in engineering: An ABET 2000 challenge. Science and Engineering Ethics, 9(4), 543-568.

[3]. Finelli, C. J., Harding, T. S., \& Carpenter, D. D. (2007). Academic integrity among engineering undergraduates: Seven years of research by the E 3 Team. Materials Engineering, 51.

[4]. Blau, I., \& Eshet-Alkalai, Y. (2017). The ethical dissonance in digital and non-digital learning environments: Does technology promotes cheating among middle school students?. Computers in Human Behavior, 73, 629-637.
[5]. Davies, L. J. P., \& Howard, R. M. (2016). Plagiarism and the internet: fears, facts, and pedagogies. Handbook of academic integrity, 591.

[6]. Friedman, A., Blau, I., \& Eshet-Alkalai, Y. (2016). Cheating and Feeling Honest: Committing and Punishing Analog versus Digital Academic Dishonesty Behaviors in Higher Education. Interdisciplinary Journal of ELearning \& Learning Objects, 12.

[7]. Mellar, H., Peytcheva-Forsyth, R., Kocdar, S., Karadeniz, A., \& Yovkova, B. (2018). Addressing cheating in e-assessment using student authentication and authorship checking systems: teachers' perspectives. International Journal for Educational Integrity, 14(1), 2.

[8]. Kocdar, S., Karadeniz, A., Peytcheva-Forsyth, R., \& Stoeva, V. (2018). Cheating and plagiarism in eassessment: students' perspectives. Open Praxis, 10(3), 221-235.

[9]. Pierce, J., \& Zilles, C. (2017, March). Investigating student plagiarism patterns and correlations to grades. In Proceedings of the 2017 ACM SIGCSE Technical Symposium on Computer Science Education (pp. 471476).

[10]. Peytcheva-Forsyth, R., Aleksieva, L., \& Yovkova, B. (2018, December). The impact of technology on cheating and plagiarism in the assessment-The teachers' and students' perspectives. In AIP conference proceedings(Vol. 2048, No. 1, p. 020037). AIP Publishing LLC.

[11]. Šprajc, P., Urh, M., Jerebic, J., Trivan, D., \& Jereb, E. (2017). Reasons for plagiarism in higher education. Organizacija, 50(1), 33-45.

[12]. Teodorescu, D., \& Andrei, T. (2009). Faculty and peer influences on academic integrity: College cheating in Romania. Higher Education, 57(3), 267282.

[13]. Ives, B., Alama, M., Mosora, L. C., Mosora, M., Grosu-Radulescu, A. I., Cazan,A.M. ...\& Dutu, A., (2017). Patterns and predictors of academic dishonesty in Romanian university students. Higher Education, 74(5), 815-831.

[14]. Rujoiu, O., \& Rujoiu, V. (2014, November). Academic dishonesty and workplace dishonesty: an overview. In Proc. Int. Manage. Conf (Vol. 8, pp. 928-938).

[15]. Teixeira, A. A., \& Rocha, M. F. (2006). Academic cheating in Austria, Portugal, Romania and Spain: A comparative analysis. Research in Comparative and International education, 1(3), 198-209.

[16]. Ogrutan, P., Cazan, A. M., \& Aciu, L. E. (2017). Difficulties of evolution from imitation to creativity in engineering education. The International journal of engineering education, 33(6), 1815-1823.

[17]. Giroux, H. (2002). Neoliberalism, corporate culture, and the promise of higher education: The University as a democratic public sphere. Harvard educational review, 72(4), 425-464. 